\title{
Publication trends in high impact journal: the case of World Psychiatry
}

\begin{tabular}{|r|l|}
\hline Journal: & Library Hi Tech News \\
\hline Manuscript ID & LHTN-08-2017-0060 \\
\hline Manuscript Type: & Feature Article \\
\hline Date Submitted by the Author: & 11 -Aug-2017 \\
\hline Complete List of Authors: & $\begin{array}{l}\text { Elango, Bakthavachalam; IFET College of Engineering, Library } \\
\text { Hartley, James; Keele University }\end{array}$ \\
\hline Keywords: & $\begin{array}{l}\text { Scientometrics, Journal, World Psychiatry, Bibliometrics, International } \\
\text { Collaboration, Keyword Analysis }\end{array}$ \\
\hline
\end{tabular}

SCHOLARONE ${ }^{\text {IT }}$

Manuscripts 
Publication trends in high impact journal: the case of World Psychiatry

\begin{abstract}
The aim of this paper is to examine the bibliometric characteristics of papers published in a high impact journal World Psychiatry during the period 2006-2015. This study covers authorship patterns, annual growth, impact factors, document types, top contributors, international collaborations, highly cited papers and keyword analyses. More than half of the publications were by editorial materials and number of publications from Low and Middle Income Countries (LMIC) is very low when compared to proportion of editorial board members. Almost $40 \%$ of papers came from the USA and editorial board members had considerable number of papers. Kings College London led the institutions.
\end{abstract}

Keywords: Bibliometrics, Scientometrics, Journal, International collaborations, World Psychiatry

\title{
Introduction
}

Scientometrics is a scientific field dealing with all aspects of people or groups of people, matter and phenomena in science and their relationships. Common research tools in this field are bibliometric methods for analyzing publication patterns, and such tools have been widely applied to measure scientific production and research trends in many academic journals ranging from science to engineering and medicine (e.g., Arya 2013; Elango and Rajendran 2012; Jain et al. 2015; Kalita 2016; Khan 2016; Rajendran et al. 2011; Santhanakarthikeyan et al. 2014; Srirak and Sirisathitkul 2016; Young et al. 2015). World Psychiatry is the official journal of the World Psychiatric Association (WPA). It is circulated free to members, and aims to disseminate research findings in the field of mental health. There have been three issues per year since 2002, and World Psychiatry has been 
published in collaboration with Wiley-Blackwell since 2008. The journal has been abstracted and indexed in both the Science Citation Index Expanded and the Social Science Citation Index of Web of Science since 2006.

World Psychiatry currently has an impact factor of 26.56 (JCR 2017) and is the highest ranked journal of the 140 journals indexed under the category of Psychiatry. According to JCR 2016, it is ranked $34^{\text {th }}$ in SCIE and $1^{\text {st }}$ in SSCI in terms of its impact factor. The journal is available in English and other national languages such as Arabic, Chinese, French, Russian, Spanish and Turkish. The editor in chief is Prof. Mario Maj of Primo Policlinico Universitario, Italy (and there are 30 people on the editorial and advisory board).

The major objectives of the journal are (Maj 2010): (a) to reach as many psychiatrists of the various countries for disseminating the information on recent research developments in clinical as well as in a language that can be assimilated by the vast majority of them (b) to support the voice of psychiatrists of different world regions by encouraging submission of research papers, commentaries and reports.

\section{Objectives}

The major objectives of this study are to study:

yearly growth

authorship pattern

citation pattern and the growth of the impact factor

prolific contributors - authors, institutes and countries

performance of editors

highly cited papers

trends in keywords 


\section{Data and methodology}

The data for this study were obtained from Thompson Reuters' 'Web of Science'. Publication details were extracted for the journal title "World Psychiatry". Software programs such as "Histcite", "intcoll.exe" and "Pajek" were used to analyze these publications and to determine international collaboration among different countries. Further, "Leximancer", a computer aided program was used to generate concept map. Manual coding was carried out to determine the number of authors who contributed to individual papers.

\section{Results}

A total of 673 papers were published in World Psychiatry from 2006 to 2015. Figure 1 shows that the highest number of papers $(\mathrm{n}=98)$ was published in 2015 , and the lowest number $(\mathrm{n}=51)$ in 2010. Figure 1 shows that there was a slight decline in the number of papers published between 2006 and 2010 but a steady increase after that.

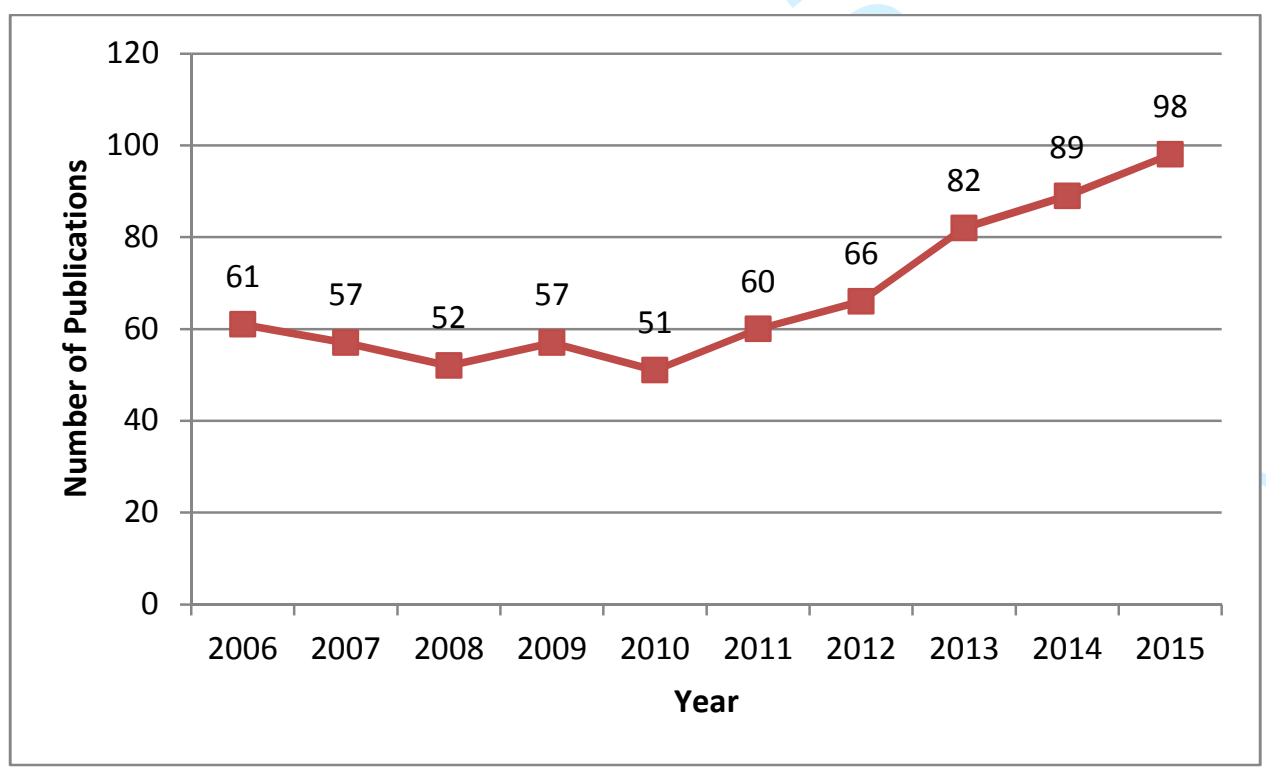

Figure 1 - Yearly publication output

\section{Document type}

Scientific papers are indexed under various document types in the Web of Science, and Table 1 shows the distribution of papers in World Psychiatry by document type. More than $97 \%$ of the 
papers were published as editorial materials (56\%), articles (31.7\%) and letters $(9.5 \%)$. Very few publications were published as reviews, news items, etc. This large percentage of papers published as editorial materials contrasts with that reported in an earlier study also on high impact journal Nature Nanotechnology where more than $50 \%$ of publications were published as articles (Elango 2017). As the journal is on organ of an international professional association, the journal expects to publish commentaries or similar items on specific themes to educate their members or the purpose to create awareness.

Table 1 - Documents Types in World Psychiatry

\begin{tabular}{|l|c|c|}
\hline Document Type & TP & $\%$ \\
\hline Editorial Material & 379 & 56.32 \\
\hline Article & 213 & 31.65 \\
\hline Letter & 64 & 9.51 \\
\hline Review & 7 & 1.04 \\
\hline News Item & 6 & 0.89 \\
\hline Correction & 2 & 0.30 \\
\hline Article; Proceedings Paper & 1 & 0.15 \\
\hline Biographical-Item & 1 & 0.15 \\
\hline Total & 673 & 100 \\
\hline
\end{tabular}

\section{Impact factors}

Table 2 provides information about the impact factor and its growth for World Psychiatry. The journal received its first impact factor of 3.896 in the 2008. Since that date, the impact factor has increased gradually to reach 20.205 in 2015 . This increase can be partly attributed to some popular studies that were published in 2013 and 2014 (e.g., Andersson et al, 2014; Chesney et al, 2014; and Cuthbert, 2014). In terms of growth, however, more than $40 \%$ of the growth in the journal's impact factor occurred between 2012 and 2013 and the lowest growth occurred in 2014. Overall, there was almost 400\% growth in the impact factor for World Psychiatry from 2008 to 2015. 
Table 2 - Impact factor and its growth

\begin{tabular}{|l|c|l|}
\hline Year & IF & Growth in \% \\
\hline 2008 & 3.896 & -- \\
\hline 2009 & 4.375 & 12.29 \\
\hline 2010 & 5.562 & 27.13 \\
\hline 2011 & 6.233 & 12.06 \\
\hline 2012 & 8.974 & 43.98 \\
\hline 2013 & 12.846 & 43.15 \\
\hline 2014 & 14.225 & 10.73 \\
\hline 2015 & 20.205 & 42.04 \\
\hline
\end{tabular}

\section{Authorship patterns}

Table 3 provides information about authorship patterns among the publications of World Psychiatry and the number of citations per paper. There were 1997 authors for the 672 papers, with almost 3 authors per paper. The range of authorship lay between 1 and 40 authors per paper. (Only one paper was anonymous in 2011. This was published by World Health Organization (2011) and dealt with the revision ICD-10 classification. ICD-10 is the tenth revision of International Statistical Classification of Diseases and related Health Problems by the World Health Organization. It contains codes for diseases, signs and symptoms, abnormal findings, complaints, social circumstances, and external causes of injury or diseases. Codes are grouped under 22 chapters and made available online at http://apps.who.int/classifications/icd10/browse/2010/en.

More than half of the papers published in World Psychiatry were by single authors $(51.71 \%)$ followed by two authors $(17.38 \%)$ and three authors $(9.81 \%)$. In terms of citation impact, papers published between 2006 and 2015 received on average 12.19 citations. Only single authored papers received lower citations per person than the average except for papers 
with nine authors. Papers with co-authors had more citations and this result agrees with those found in earlier studies (e.g., Hartley and Cabanac, 2015; Leimu and Koricheva, 2005).

Table 3 - Authorship patterns and citations per paper

\begin{tabular}{|l|l|l|l|}
\hline \# Authors & \# Papers & \% of 673 & CPP \\
\hline 1 & 348 & 51.71 & 7.11 \\
\hline 2 & 117 & 17.38 & 10.92 \\
\hline 3 & 66 & 9.81 & 15.86 \\
\hline 4 & 30 & 4.46 & 20.37 \\
\hline 5 & 27 & 4.01 & 11.85 \\
\hline 6 & 18 & 2.67 & 17.67 \\
\hline 7 & 11 & 1.63 & 15.91 \\
\hline 8 & 10 & 1.49 & 12.50 \\
\hline 9 & 5 & 0.74 & 10 \\
\hline$>9$ & 40 & 5.94 & 43.57 \\
\hline Anon & 1 & 0.15 & 62 \\
\hline Total & 673 & 100 & 12.19 \\
\hline
\end{tabular}

\section{Most prolific authors}

1499 unique authors were responsible for 672 papers published during 2006-2015. Majority of the authors $(\sim 82 \%)$ had only one paper in the first ten years period and only $11 \%$ of authors had two papers. Table 4 lists the 14 most productive authors with at least 7 papers each: among these, four are editorial board members of the journal. Maj (who is also the editor-in-chief of the journal) contributed most papers to the journal (23 papers), followed by Gureje (11) and Corell (10). Maj contributed most of his papers as editorial material. In terms of citation impact, De Hert had the highest CPP with 93.63 followed by Correl $(\mathrm{CPP}=61.3)$ and Stein $(\mathrm{CPP}=60)$.

Table 4 - Prolific authors (TP $\geq 7)$

\begin{tabular}{|l|c|c|c|}
\hline \multicolumn{1}{|c|}{ Author } & TP & TC & CPP \\
\hline Maj M & 23 & 388 & 16.87 \\
\hline Gureje O & 11 & 649 & 59.00 \\
\hline
\end{tabular}




\section{Performance of editorial board members}

Table 5 provides the information about the number of publications with their local (number of citations among the publications of World Psychiatry) and global citation scores (number of citations from the core collections of Thomson Reuters). The journal has 10 editorial advisory board members from low-and-middle income countries ( $32 \%$ of 31 ) and this is the only journal having one third of editorial board members from low-and-middle income countries among top ten general psychiatry journals (Pike et al. 2017). Of the editorial board members, 9 members did not publish any paper in the journal. Among the editorial board members $(\mathrm{N}=31)$, chief editor Maj published most papers $(\mathrm{n}=23)$ and also received a number of citations from World Psychiatry publications as well as from other publications in WoS. Advisory board member Katschnig received the highest citations per paper with 51.5 (GCScore) even though he only published two papers in the journal. Other papers by editorial board members Kallivayalil, LiehMak, Lolas, Lopez-Ibor, Munk-Jorgensen, and Okasha also received citations from other publications in WoS, but those publications have not been cited in subsequent World Psychiatry papers.

Table 5 - Papers by editorial board members 


\begin{tabular}{|c|c|c|c|c|c|c|c|c|}
\hline Author & Type & Country & TP & \#CP & LCS & LCS / TP & GCS & GCS / TP \\
\hline Maj M & Editor & Italy & 23 & 4 & 120 & 5.22 & 388 & 16.87 \\
\hline Sartorius N & $\mathrm{AB}$ & Switzerland & 9 & 4 & 17 & 1.89 & 109 & 12.11 \\
\hline Parnas J & $\mathrm{AB}$ & Denmark & 8 & 3 & 23 & 2.88 & 107 & 13.38 \\
\hline Mezzich JE & $\mathrm{AB}$ & USA & 8 & 0 & 6 & 0.75 & 110 & 13.75 \\
\hline Bhugra D & EB & UK & 7 & 3 & 17 & 2.43 & 68 & 9.71 \\
\hline Patel V & $\mathrm{AB}$ & India & 6 & 4 & 6 & 1 & 97 & 16.17 \\
\hline Javed A & EB & UK / Pakistan & 5 & 2 & 14 & 2.8 & 53 & 10.60 \\
\hline Herrman $\mathrm{H}$ & EB & Australia & 5 & 5 & 16 & 3.2 & 94 & 18.80 \\
\hline Njenga F & $\mathrm{AB}$ & Kenya & 3 & 1 & 3 & 1 & 38 & 12.67 \\
\hline Moussaoui D & $\mathrm{AB}$ & Morocco & 3 & 1 & 9 & 3 & 39 & 13 \\
\hline Alarcon RD & $\mathrm{AB}$ & USA & 3 & 1 & 9 & 3 & 39 & 13 \\
\hline Kallivayalil RA & EB & India & 2 & 1 & 0 & 0 & 5 & 2.5 \\
\hline Okasha A & $\mathrm{AB}$ & Egypt & 2 & 1 & 0 & 0 & 18 & 9 \\
\hline $\begin{array}{l}\text { Munk-Jorgensen } \\
\mathrm{P}\end{array}$ & $\mathrm{AB}$ & Denmark & 2 & 1 & 0 & 0 & 10 & 5 \\
\hline Lopez-Ibor JJ & $\mathrm{AB}$ & Spain & 2 & 1 & 0 & 0 & 15 & 7.5 \\
\hline Lolas F & $\mathrm{AB}$ & Chile & 2 & 1 & 0 & 0 & 16 & 8 \\
\hline Katschnig H & $\mathrm{AB}$ & Australia & 2 & 2 & 8 & 4 & 103 & 51.5 \\
\hline Riba M & EB & USA & 1 & 0 & 3 & 3 & 15 & 15 \\
\hline Belfort E & EB & Venezuela & 1 & 0 & 2 & 2 & 3 & 3 \\
\hline Lieh-Mak F & $\mathrm{AB}$ & China & 1 & 0 & 0 & 0 & 0 & 0 \\
\hline Jorge M & $\mathrm{AB}$ & Brazil & 1 & 1 & 3 & 3 & 15 & 15 \\
\hline Soghoyan A & EB & Armenia & 0 & 0 & - & - & - & - \\
\hline Takeda M & EB & Japan & 0 & 0 & - & - & - & - \\
\hline Akiskal H S & $\mathrm{AB}$ & USA & 0 & 0 & - & - & - & - \\
\hline Costa e Silva J A & $\mathrm{AB}$ & Brazil & 0 & 0 & - & - & - & - \\
\hline $\operatorname{Cox} \mathrm{J}$ & $\mathrm{AB}$ & UK & 0 & 0 & - & - & - & - \\
\hline Ruiz P & $\mathrm{AB}$ & USA & 0 & 0 & - & - & - & - \\
\hline Tasman A & $\mathrm{AB}$ & USA & 0 & 0 & - & - & - & - \\
\hline Tyano $\mathrm{S}$ & $\mathrm{AB}$ & Israel & 0 & 0 & - & - & - & - \\
\hline Zohar J & $\mathrm{AB}$ & Israel & 0 & 0 & - & - & - & - \\
\hline \multicolumn{9}{|c|}{ EB - Editorial Board $(n=8)$, AB0 - Advisory Board $(n=22)$} \\
\hline
\end{tabular}

\section{Most prolific institutes}

Among the 673 papers, 38 did not provide any information about where the authors were based.

Over all, authors from 762 institutions were responsible for 635 papers in the first ten years period and majority of the institutions (68\%) had only one paper. Table 6 lists the 13 most 
productive institutions with at least 10 papers each. The single heading WHO groups together institutions that include the various regional offices and departments of World Health Organization located in China, Switzerland, Italy, Egypt, Philippines, UK and Denmark. All the 13 most productive institutions are universities that provide general education except $\mathrm{WHO}$, and New York State Psychiatric Institute and Hospital. As can be seen, the list is headed by Kings College London with 50 papers, followed by the University of Naples (28) and Harvard University (24). In contrast to this, Harvard University was the top most productive institution in the high impact journal Nature Nanotechnology (Elango 2017). Indeed, the top most productive institution in the field of psychiatry is Harvard University (Igoumenou et al. 2014) and Harvard University also ranks first for psychology (Ho and Hartley, 2016).

Table 6 - Most productive institutions $(\mathrm{TP} \geq 10)$

\begin{tabular}{|l|l|l|}
\hline Institution & TP & \% of 635 \\
\hline Kings Coll London, UK & 50 & 7.87 \\
\hline Univ Naples SUN, Italy & 28 & 4.40 \\
\hline Harvard Univ, USA & 24 & 3.78 \\
\hline Columbia Univ, USA & 23 & 3.62 \\
\hline Univ Melbourne, Australia & 22 & 3.46 \\
\hline WHO & 17 & 2.68 \\
\hline Univ Copenhagen, Denmark & 15 & 2.36 \\
\hline NYU, USA & 14 & 2.20 \\
\hline $\begin{array}{l}\text { New York State Psychiat Inst \& Hosp, } \\
\text { USA }\end{array}$ & 13 & 2.04 \\
\hline Yale Univ, USA & 13 & 2.04 \\
\hline Karolinska Inst, Sweden & 12 & 1.89 \\
\hline UCL, USA & 10 & 1.57 \\
\hline Univ Cape Town, South Africa & 10 & 1.57 \\
\hline
\end{tabular}

\section{Most productive countries}

Seventy-five of the 673 papers did not indicate where the authors originated from but the remaining data show that authors located in 64 countries were responsible for 598 papers. 
Among these 64 countries, only 11 had more than 20 papers during 2006-2015 in World Psychiatry. It is observed from the analysis that the contribution of low-and-middle countries is only $11 \%$ of total papers in the first ten years period and this is contrast to the proportion of editorial board members (32\%). Table 7 lists these most productive countries. The top two, USA and UK, accounted for $62 \%$ of total papers and this result is in agreement with the findings of an earlier study on scientific production in psychiatry (Biglu et al. 2011).

Figure 2 visualizes the network of international collaboration between these authors. Each node represents one country and the interconnecting (edge) line denotes the collaboration between the countries. Countries having more collaborations with other countries fall in the center of the network (e.g. USA, Japan and Spain) while countries having less collaborations are mapped in the outer layer of the network (e.g. Russia, Thailand and Vietnam). Two countries (Tunisia and South Korea) were not integrated in this collaboration network as these countries did not have international collaboration.

Table 7 - Most productive countries (TP $\geq 20)$

\begin{tabular}{|l|r|r|}
\hline Country & TP & \% of 598 \\
\hline USA & 234 & 39.13 \\
\hline UK & 139 & 23.24 \\
\hline Italy & 63 & 10.54 \\
\hline Australia & 56 & 9.36 \\
\hline Germany & 51 & 8.53 \\
\hline Switzerland & 42 & 7.02 \\
\hline Spain & 34 & 5.69 \\
\hline Netherlands & 31 & 5.18 \\
\hline Canada & 30 & 5.02 \\
\hline Denmark & 27 & 4.52 \\
\hline India & 24 & 4.01 \\
\hline
\end{tabular}


Figure 2 - International collaboration network

\section{Highly cited papers}

Recently, Elango (2016) proposed an innovative method to determine highly cited papers and the following formula has been employed here:

$$
M C \text { in } H C P=\frac{T C}{T P} X \frac{\sum Y n-Y i}{N}
$$

Where, $\mathrm{MC}=$ Minimum Citations

$$
\begin{aligned}
& \mathrm{HCP}=\text { Highly Cited Papers } \\
& \mathrm{TC}=\text { Total citations received by the papers (i.e. } 8204) \\
& \mathrm{TP}=\text { Total papers (i.e. } 673 \text { ) } \\
& \mathrm{Yn}=\text { Date of database access for citations (accessed on } 28.06 .2016 \text { and taken as 2015) } \\
& \mathrm{Yi}=\text { One of the year of publications in a data set (i.e. } 2006,2007, \ldots .2015) \\
& \mathrm{N}=\text { Number of years (i.e. } 10)
\end{aligned}
$$

By substituting the appropriate values for World Psychiatry in the above formula, the minimum number of citations needed for a publication to be called a highly cited paper is 55 . In this study 25 publications met this criterion and Table 8 lists their characteristics. The citations received by 
the 25 most cited papers totaled 2697 ( $\sim 33 \%)$ of all citations, with an average of 108 citations each. Of these 25 papers, eight had a single author and nine involved international collaboration. Thus almost $70 \%$ of the most cited papers were co-authored, a result that supports the notion that that co-authored papers generally receive more citations than single authored ones (Hartley \& Cabanac, 2016) . Only 4 (16\%) papers were published as reviews while the remaining 21 papers (84\%) were articles.

The results of face-to-face community surveys conducted on lifetime prevalence and ageof-onset distributions in seventeen countries in Africa, Asia, the Americas, Europe, and the Middle East were published in the top cited paper (Kessler et al. 2007). A group led by De Hert has three highly cited papers (top $2^{\text {nd }}, 3^{\text {rd }}$ and $6^{\text {th }}$ papers): a review was conducted on the prevalence and incidence of metabolic syndrome in patients suffering from Schizophrenia (De Hert et al. 2009) and reported prevalence rates of different physical illnesses as well as important individual lifestyle choices, side effects of psychotropic treatment and disparities in health care access, utilization and provision that contribute to these poor physical health outcomes (De Hert et al. 2011a; 2011b).

Table 8 - Characteristics of highly cited papers (TC $\geq 55)$

\begin{tabular}{|l|l|l|l|l|}
\hline Author & Title & TC & Coll. Type & DT \\
\hline Kessler et al. (2007) & $\begin{array}{l}\text { Lifetime prevalence and age-of-onset distributions of mental } \\
\text { disorders in the World Health Organization's World Mental } \\
\text { Health Survey Initiative }\end{array}$ & 378 & International & Article \\
\hline De Hert et al. (2011) & $\begin{array}{l}\text { Physical illness in patients with severe mental disorders. I. } \\
\text { Prevalence, impact of medications and disparities in health care }\end{array}$ & 316 & International & Article \\
\hline De Hert et al. (2009) & Metabolic syndrome in people with schizophrenia: a review & 175 & International & Review \\
\hline $\begin{array}{l}\text { McGorry, Killackey \& } \\
\text { Yung (2008) }\end{array}$ & $\begin{array}{l}\text { Early intervention in psychosis: concepts, evidence and future } \\
\text { directions }\end{array}$ & 144 & National & Review \\
\hline Cuthbert (2014) & $\begin{array}{l}\text { The RDoC framework: facilitating transition from ICD/DSM to } \\
\text { dimensional approaches that integrate neuroscience and } \\
\text { psychopathology }\end{array}$ & 143 & Single authored & Article \\
\hline De Hert et al. (2011) & $\begin{array}{l}\text { Physical illness in patients with severe mental disorders. II. } \\
\text { Barriers to care, monitoring and treatment guidelines, plus } \\
\text { recommendations at the system and individual level }\end{array}$ & 142 & International & Article \\
\hline Wang et al. (2007) & $\begin{array}{l}\text { Delay and failure in treatment seeking after first onset of mental } \\
\text { disorders in the World Health Organization's World Mental } \\
\text { Health Survey Initiative }\end{array}$ & 127 & International & Article \\
\hline
\end{tabular}




\begin{tabular}{|c|c|c|c|c|}
\hline $\begin{array}{l}\text { Corrigan, Larson \& Rusch } \\
(2009)\end{array}$ & $\begin{array}{l}\text { Self-stigma and the why try" effect: impact on life goals and } \\
\text { evidence-based practices" }\end{array}$ & 123 & Co-authored & Article \\
\hline McFarlane, AC (2010) & $\begin{array}{l}\text { The long-term costs of traumatic stress: intertwined physical and } \\
\text { psychological consequences }\end{array}$ & 93 & Single authored & Article \\
\hline Cicchetti, D & $\begin{array}{l}\text { Resilience under conditions of extreme stress: a multilevel } \\
\text { perspective }\end{array}$ & 86 & Single authored & Article \\
\hline $\begin{array}{l}\text { Bond, GR; Drake, RE; } \\
\text { Becker, DR (2012) }\end{array}$ & $\begin{array}{l}\text { Generalizability of the Individual Placement and Support (IPS) } \\
\text { model of supported employment outside the US }\end{array}$ & 77 & Institutional & Article \\
\hline Black, DW (2007) & A review of compulsive buying disorder & 76 & Single authored & Review \\
\hline $\begin{array}{l}\text { Wakefield, JC; First, MB } \\
\text { (2012) }\end{array}$ & $\begin{array}{l}\text { Validity of the bereavement exclusion to major depression: does } \\
\text { the empirical evidence support the proposal to eliminate the } \\
\text { exclusion in DSM-5? }\end{array}$ & 69 & National & Article \\
\hline Cloninger, CR (2006) & $\begin{array}{l}\text { The science of well-being: an integrated approach to mental } \\
\text { health and its disorders }\end{array}$ & 68 & Single authored & Article \\
\hline Katschnig, H (2010) & $\begin{array}{l}\text { Are psychiatrists an endangered species? Observations on } \\
\text { internal and external challenges to the profession }\end{array}$ & 67 & Single authored & Review \\
\hline Thornicroft et al. (2010) & $\begin{array}{l}\text { WPA guidance on steps, obstacles and mistakes to avoid in the } \\
\text { implementation of community mental health care }\end{array}$ & 66 & International & Article \\
\hline Sato, M (2006) & Renaming schizophrenia: a Japanese perspective & 64 & Single authored & Article \\
\hline Reed et al. (2011) & $\begin{array}{l}\text { The WPA-WHO Global Survey of Psychiatrists' Attitudes } \\
\text { Towards Mental Disorders Classification }\end{array}$ & 63 & International & Article \\
\hline Sartorius et al. (2010) & $\begin{array}{l}\text { WPA guidance on how to combat stigmatization of psychiatry } \\
\text { and psychiatrists }\end{array}$ & 63 & International & Article \\
\hline WHO, 2011 & $\begin{array}{l}\text { A conceptual framework for the revision of the ICD-10 } \\
\text { classification of mental and behavioural disorders }\end{array}$ & 62 & Corporate & Article \\
\hline Hasler, G (2010) & $\begin{array}{l}\text { Pathophysiology of depression: do we have any solid evidence } \\
\text { of interest to clinicians? }\end{array}$ & 60 & Single authored & Article \\
\hline Andersson et al. (2014) & $\begin{array}{l}\text { Guided Internet-based vs. face-to-face cognitive behavior } \\
\text { therapy for psychiatric and somatic disorders: a systematic } \\
\text { review and meta-analysis }\end{array}$ & 60 & International & Article \\
\hline Zisook, S; Shear, K (2009) & Grief and bereavement: what psychiatrists need to know & 59 & Institutional & Article \\
\hline Braff et al. (2008) & Advances in endophenotyping schizophrenia & 58 & National & Article \\
\hline Morgan et al. (2006) & $\begin{array}{l}\text { First episode psychosis and ethnicity: initial findings from the } \\
\text { AESOP study }\end{array}$ & 58 & Institutional & Article \\
\hline
\end{tabular}

\section{The content: An analysis of keywords}

The content of documents can be analyzed by examining key words. Here two types of

keywords were analyzed: keywords provided by the authors and words in the publication titles.

The authors provided 603 unique keywords. Table 9 lists those author keywords that occurred

five or more times. It can be seen that the top six of these author keywords (that appeared 10 times or more) were schizophrenia (chronic and mental disorder), depression (common but serious mood disorder), mental health (psychological well-being or absence of mental illness), diagnosis (general term in the field of medicine and it is the identification of the nature of an illness), classification (more general term) and psychosis (loss of contact with reality). Figure 3 
shows how the top keywords, schizophrenia, mental, diagnosis and psychosis can be visualized in a concept map (Figure 3).

Table 9 - Distribution of top author keywords $(\geq 5)$

\begin{tabular}{|l|l|l|}
\hline Author Keywords & $\#$ & \% of 673 \\
\hline Schizophrenia & 31 & 4.61 \\
\hline Depression & 19 & 2.82 \\
\hline Mental Health & 17 & 2.53 \\
\hline Diagnosis & 15 & 2.23 \\
\hline Classification & 11 & 1.63 \\
\hline Psychosis & 10 & 1.49 \\
\hline Severe Mental Illness & 9 & 1.34 \\
\hline Community Mental Health Care & 9 & 1.34 \\
\hline Mental Disorders & 7 & 1.04 \\
\hline Adolescents & 6 & 0.89 \\
\hline Mental Health Services & 6 & 0.89 \\
\hline Comorbidity & 6 & 0.89 \\
\hline Major Depression & 5 & 0.74 \\
\hline Anxiety & 5 & 0.74 \\
\hline Mood Disorders & 5 & 0.74 \\
\hline Post-traumatic Stress Disorder & 5 & 0.74 \\
\hline Psychiatry & 5 & 0.74 \\
\hline Stigma & 5 & 0.74 \\
\hline Mental Illness & 5 & 0.74 \\
\hline Bipolar Disorder & 5 & 0.74 \\
\hline Primary Care & 5 & 0.74 \\
\hline
\end{tabular}

A software analysis tool called "Leximancer" (retrieved from www.leximancer.com) was used to build a concept map for the titles of publication in World Psychiatry. For this, a text file containing titles of publications was constructed and uploaded into the software tool. Figure 3 shows that there were eight important themes in the titles of papers published in World Psychiatry: model, diagnosis and practice are more general terms in the field of medicine. Psychiatric is the medical specialty which deals the study of mental disorder. Schizophrenia is the severe mental disorder and Psychosis is characterized as the loss of contact with reality. 
Mental is a term related to the mind and this is term can be used in the combination of health or disorder, in the field of psychiatry (see table 9). It is observed from the figure 3 that the journal focusing only on the research comes under the scope of the journal.

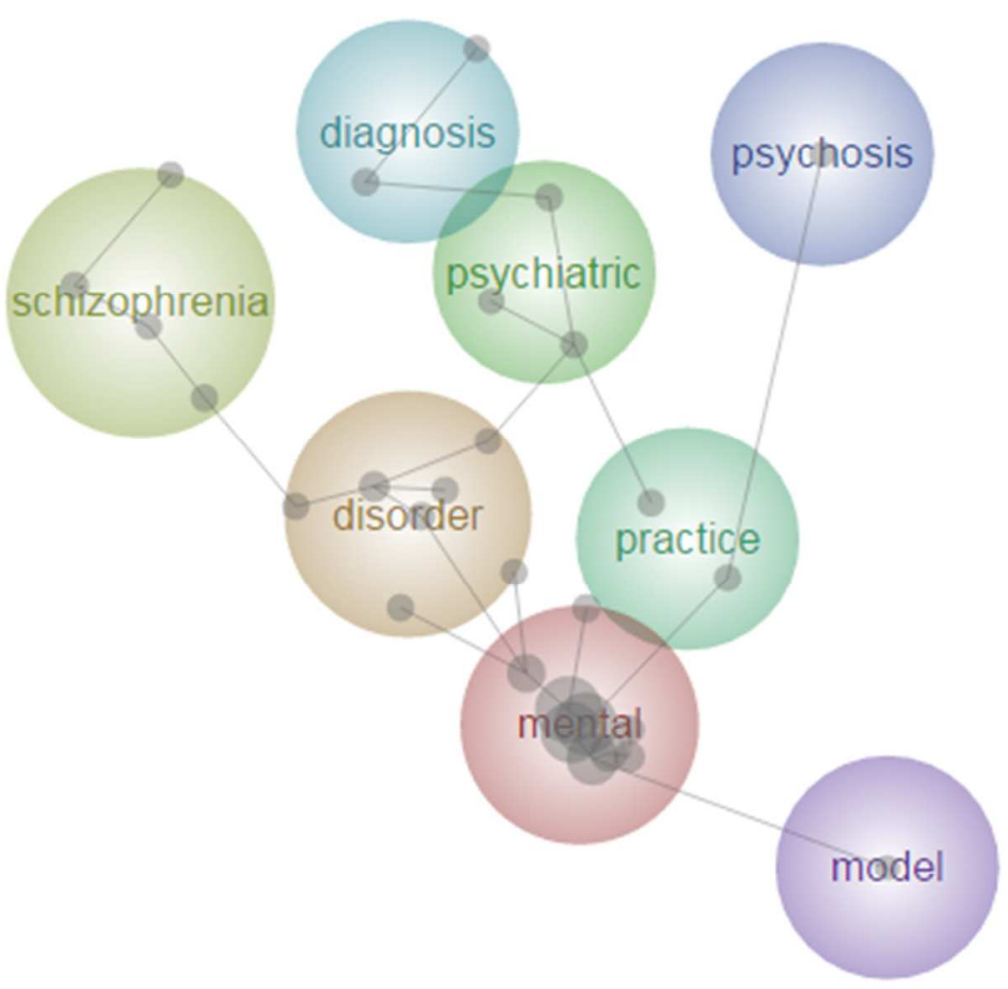

Figure 3 - Concept map of publication titles

\section{Summary and conclusion}

We carried out a scientometric analysis on publications in the high impact psychiatry journal World Psychiatry during the period 2006-2015, using various software programs along with traditional scientometric indicators.

Our study yielded some interesting findings about the publication trends of the journal. About $51 \%$ of total papers were contributed by single authors and it is because of more than half of the papers were published as editorial materials. The editors of the journal also contributed considerable number of publications during the study period and more than $50 \%$ of the publications were published as editorial material. The contribution of low-middle-income 
countries is very low when compared to the number of editorial board members. Together the USA and the UK contributed more than $60 \%$ of the publications, and Kings College London led the contributing institutions.

The top three most frequently used keywords were schizophrenia, depression and mental health. In addition, eight themes were identified among the publication titles and five of them (Schizophrenia, Psychosis, Psychiatric, Diagnosis and Disorder) are related to the field of this journal. Further, it is suggested that the software tool Leximancer can be used to determine whether a specific journal focuses only on the research under the scope of the journal.

This study highlighted the variety of characteristics of the journal World Psychiatry that can be used to understand the characteristics of a high impact psychiatry journal. Further, bibliometric studies of this kind will help us to assess the publication patterns of specific journals and core authors, as well as establish international partners for future research projects.

\section{References}

Arya, C. (2013). Sadhana - Academy Proceedings in Engineering Science: a scientometric analysis. Sadhana, 38 (4), 761-771.

Biglu, S., Biglu, M.H. and Falk, C. (2011). Scientometric study of scientific production in psychiatry. European Psychiatry, 26 (Supplement 1), 515.

De Hert, M., et al. (2009). Metabolic syndrome in people with schizophrenia: a review. World Psychiatry, 8 (1), 15-22.

De Hert, M., et al. (2011a). Physical illness in patients with severe mental disorders. I. Prevalence, impact of medications and disparities in health care. World Psychiatry, 10 (1), 52-77. 
De Hert, M., et al. (2011b). Physical illness in patients with severe mental disorders. II. Prevalence, impact of medications and disparities in health care. World Psychiatry, 10 (2), 138-151.

Elango, B. and Rajendran, P. (2012). Authorship trends and collaboration pattern in the marine sciences literature: a scientometric study. International Journal of Information Dissemination and Technology, 2 (3), 166-169.

Elango, B. (2016). Counting the number of highly cited papers. International Research: Journal of Library and Information Science, 6 (3), 528-532.

Elango, B. (2017). Scientometric analysis of Nature Nanotechnology. Library Hi Tech News, 34 (1), 23-30.

Hartley, J \& Cabanac, G. (2015). An academic odyssey: writing over time. Scientometrics, 103 (3), 1073-1082.

Ho, Y-S. \& Hartley, J. (2016). Classic articles in Psychology in the Science Citation Index Expanded: A bibliometric analysis. British Journal of Psychology, 107 (4), 768-780.

Igoumenou, A., et al. (2014). Geographic trends of scientific output and citation practices in psychiatry. BMC Psychiatry, 14, 332. doi: 10.1186/s12888-014-0332-6

Jain, S., et al. (2015). Bibliometric analysis of Journal of Clinical and Diagnostic Research (Dentistry Section; 2007-2014). Journal of Clinical and Diagnostic Research, 9 (4), 4751.

Kalita, D. (2016). The scientometrics of Nature. Journal of Scientometric Research, 5 (2), $123-134$. 
Kessler, R., et al. (2007). Lifetime prevalence and age-of-onset distributions of mental disorders in the World Health Organization's World Mental Health Survey Initiative. World Psychiatry, 6 (3), 168-176.

Khan, I. (2016). A scientometric analysis of DESIDOC Journal of Library and Information Technology. Library Hi Tech News, 33 (7), 8-12.

Leimu, R. and Koricheva, J. (2005). Does scientific collaboration increase the effect of ecological articles? BioScience, 55 (5), 438-443.

Maj, M. (2010). The new impact factor of World Psychiatry. World Psychiatry, 9 (3), 129-130.

Majumder, A.A., et al. (2015). A bibliometric analysis of papers published in the South East Asia Journal of Public Health from 2011 to 2015. South East Asia Journal of Public Health, 5 (1), 51-54.

Pike, K.M., et al. (2017). A renewed call for international representation in editorial boards of international psychiatry journals. World Psychiatry, 16 (1), 106-107.

Rajendran, P., Jeyshankar, R. and Elango, B. (2011). Scientometric analysis of contributions to Journal of Scientific and Industrial Research. International Journal of Digital Library Services, 1 (2), 79-89.

Santhakarthikeyan, S., Grace, M. and Jeyshankar, R. (2014). Research publications to Indian Journal of Cancer: a scientometric analysis. Library Hi Tech News, 31 (3), $21-25$.

Srirak, K. and Sirisathitkul, C. (2016). Walailak Journal of Science and Technology - A scientometric analysis from 2010 to 2015. Walailak Journal of Science and Technology, 13 (6), 391-397. 
Young, L., Wilkinson, I. and Smith, A. (2015). A scientometric analysis of publications in the Journal of Business-to-Business Marketing 1993-2014. Journal of Businessto-Business Marketing, 22 (1-2), 111-123. 